\title{
Koivusta ja kuusesta paine-kuumavesiuutetun hemiselluloosaliuoksen maittavuus lypsylehmille
}

\author{
Outi Kautto $^{1)}$, Auvo Sairanen ${ }^{2)}$, Kaisa Kuoppala ${ }^{1)}$, Olli Byman ${ }^{3)}$, Hannu Ilvesniemi ${ }^{3)}$ ja Marketta \\ Rinne $^{1)}$ \\ ${ }^{1)}$ Maa- ja elintarviketalouden tutkimuskeskus MTT, Animale, 31600 Jokioinen, \\ etunimi.sukunimi@mtt.fi \\ ${ }^{2)}$ Maa- ja elintarviketalouden tutkimuskeskus MTT, Halolantie 31A, 71750 Maaninka, \\ etunimi.sukunimi@mtt.fi \\ ${ }^{3)}$ Metsäntutkimuslaitos Metla, Jokiniemenkuja 1, 01370 Vantaa, etunimi.sukunimi@metla.fi
}

\section{Tiivistelmä}

Paineistetulla kuumavesiuutolla puusta pystytään eristämään vesiliukoinen hemiselluloosafraktio. Aikaisempien tutkimusten perusteella puusta eristetty hemiselluloosa soveltuu märehtijöiden rehuksi. Prosessista tuleva hemiselluloosa on vesiliuoksessa, jonka kuivaaminen on kallista. Uutteen yhtenä käyttövaihtoehtona voisi olla hemiselluloosaliuoksen (hemiliuoksen) juottaminen sellaisenaan. Tässä kokeessa selvitettiin, miten maittavaa hemiliuos on lypsylehmille ja millaisia määriä vuorokaudessa lehmät sitä juovat.

Kuumavesiuutot suoritettiin Metlassa Vantaalla. Uuttolämpötila oli $180{ }^{\circ} \mathrm{C}$ kuuselle ja $170{ }^{\circ} \mathrm{C}$ koivulle ja virtausnopeus uuton aikana oli $20 \mathrm{l}$ minuutissa. Hemiliuosten maittavuuden selvittämiseksi tehtiin juottokoe kuudella lypsylehmällä MTT Maaningan tutkimusnavetassa tammikuussa 2013. Lehmät olivat parsissa ja niiden seosrehun kulutus ja maitomäärä mitattiin päivittäin. Kokeen alussa 2,5 päivän ajan selvitettiin lehmäkohtaisesti päivittäinen vedenkulutus. Kolmantena koepäivänä lehmät saivat tutustua liuoksiin. Neljäntenä koepäivänä suoritettiin challenge-testi kello 6-15, jonka aikana lehmät saivat juoda vain koivu- ja kuusihemiselluloosaliuoksia (koivu- ja kuusiliuoksia). Lehmät eivät 15 tunnin vesipaastosta huolimatta yhtä lehmää lukuun ottamatta juuri koskeneet hemiliuoksiin. Liuoksia alettiin laimentaa vedellä ja suhde $1 / 5$ oli sellainen, jota lehmät alkoivat juoda. Viidennestä koepäivästä kokeen loppuun liuoksia alettiin jälleen väkevöittää asteittain siten, että yhdeksäntenä eli viimeisenä koepäivänä tarjottiin jälleen laimentamattomia liuoksia. Lehmät saivat juoda vettä ainoastaan iltaisin kello 20 puolen tunnin ajan.

Koivu- ja kuusiliuoksen kuiva-ainepitoisuudet olivat 27 ja 16 g/kg. Kuusiliuos oli selvästi maittavampaa. Lehmät eivät kärsineet janoa kokeen aikana, sillä veden saanti juomalla, hemiliuoksista ja rehusta lisääntyi kokeen loppua kohti. Lehmien välillä oli suuria eroja hemiliuosten maittavuudessa. Molempien hemiliuosten säilyvyyttä seurattiin aistinvaraisesti ja ne osoittautuivat stabiileiksi.

Lehmät eivät aluksi juoneet koivu- ja kuusiliuoksia juuri lainkaan, mutta ne tottuivat niiden makuun niinikin lyhyessä ajassa kuin neljässä päivässä. Asteittaisella totuttamisella saatiin tässä kokeessa hyvä tulos. Suurimmat päivittäiset laimennettujen koivu- ja kuusiliuoksen lehmäkohtaiset juontimäärät olivat 42 ja 77 kiloa. Hemiliuosten käytön aikana ei havaittu poikkeavuuksia lehmien yleisessä voinnissa, rehujen vapaaehtoisessa syönnissä, maitotuotoksissa tai maidon pitoisuuksissa.

Asiasanat: hemiselluloosa, pressurized hot water extraction, puu, vedenkulutus 


\section{Johdanto}

Paine-kuumavesiuutolla puusta pystytään eristämään vesiliukoinen hemiselluloosafraktio (Leppänen ym. 2011). Alustavien tutkimusten perusteella eristetty hemiselluloosa soveltuu märehtijöiden rehuksi (Kuoppala ym. 2012, Sormunen-Cristian ym. 2012). Sillä on todettu olevan muun muassa kuidun sulatusta parantava vaikutus (Herrick et al. 2011).

Prosessin tuloksena tuotetussa hemiselluloosaliuoksessa on kuiva-ainetta vain muutama prosentti. Yhtenä hyödyntämisvaihtoehtona on juottaa liuos sellaisenaan eläimille. Menetelmää on käytetty mm. joidenkin ravintoaineiden ja muiden nestemäisten sivutuotteiden annosteluun naudoille (esim. Panjaitan et al. 2010). Suomessa lehmät pihatto-olosuhteissa joivat 71,5 kg vettä päivässä ja juontikertoja oli 10,4 päivässä eli lehmät joivat kerralla 7,9 kg. Juomiseen lehmät käyttivät 9 minuuttia päivässä (Kuoppala ym. 2004).

Tässä kokeessa selvitettiin, miten maittavaa hemiselluloosaliuos on lypsylehmille ja millaisia määriä vuorokaudessa lehmät sitä juovat. Hemiliuosta valmistettiin sekä havu- että lehtipuusta, jolloin raaka-aineen mahdollinen vaikutus maittavuuteen saatiin selville.

\section{Aineisto ja menetelmät}

Hemiliuokset. Läpivirtausperiaatteella toteutetut paineistetut kuumavesiuutot suoritettiin Metlassa 14. ja 15.1 2013. Raaka-aineina käytettiin erikseen havupuun ja lehtipuun sahanpurua ja molempia liuoksia valmistettiin yksi $600 \mathrm{l}$ kontti. Uuttolämpötila oli $180{ }^{\circ} \mathrm{C}$ kuuselle ja $170{ }^{\circ} \mathrm{C}$ koivulle ja virtausnopeus uuton aikana oli $20 \mathrm{l}$ minuutissa.

Hemiliuoskontit kuljetettiin MTT Maaningalle välittömästi niiden valmistuttua. Kontit säilytettiin Halolan tutkimusnavetassa viileässä. Liuoksen ja säilytyspaikan lämpötilaa seurattiin päivittäin ja tarvittaessa kontit nostettiin pienkuormaajalla ulos jäähtymään. Konttien lämpötila pyrittiin pitämään alle $+8{ }^{\circ} \mathrm{C}$ asteessa. Kokeen aikana oli pakkasta suurimman osan ajasta yli $-10{ }^{\circ} \mathrm{C}$, jolloin navetan sisälämpötila pysyi alle $+10^{\circ} \mathrm{C}$. Kolmena päivänä hemiliuoskontit nostettiin ulos jäähtymään.

Koepaikka- ja aika. Koe suoritettiin MTT Maaningan tutkimusnavetassa 14.1. - 23.1.2013. Lehmät olivat kokeen aikana parteen kytkettyinä siten, että vain joka toisessa parressa oli eläin. Näin kokeen vaatimille juomalaatikoille jäi tarpeeksi tilaa.

Kuva 1. Lehmät koeparsissa edessään vesilaatikot vedenkulutuksen mittausta varten (kuva O. Kautto).

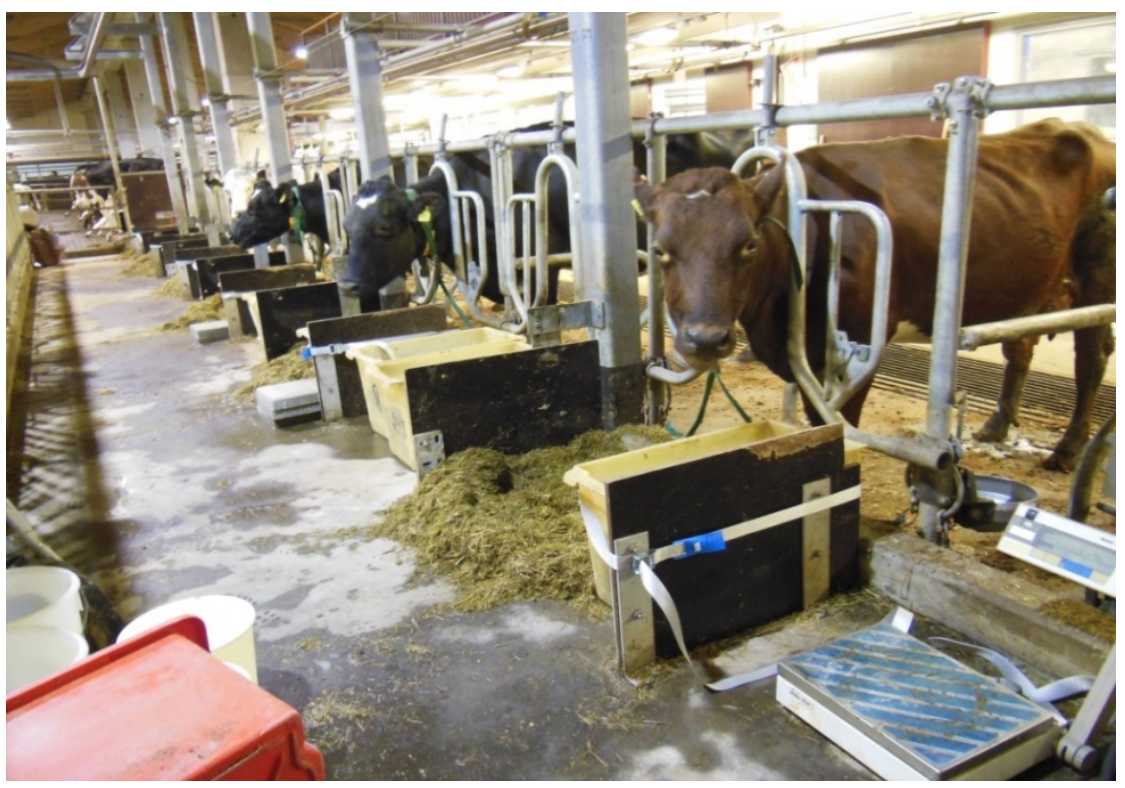


Eläimet. Kokeessa oli yhteensä kuusi lypsylehmää, joista kolme oli holstein- ja kolme ayrshirerotuista. Neljä lehmistä oli poikinut edellisenä syksynä elo-syyskuussa ja kaksi marraskuun lopussa (Taulukko 1). Yksi lehmä jouduttiin vaihtamaan ensimmäisen päivän jälkeen syömättömyyden vuoksi.

Taulukko 1. Koelehmien kuvailu.

\begin{tabular}{ccccc}
\hline Korvanumero & Rotu & Elopaino, kg & Päivää poikimisesta & Poikimakerta \\
\hline 106 & holstein & 689 & 51 & 2 \\
133 & holstein & 590 & 154 & 1 \\
140 & ayrshire & 540 & 54 & 2 \\
176 & holstein & 562 & 130 & 1 \\
4268 & ayrshire & 692 & 163 & 4 \\
3316 & ayrshire & 737 & 161 & 3 \\
\hline
\end{tabular}

Ruokinta. Lehmät saivat kokeen aikana seosrehua, jonka väkirehupitoisuus oli $480 \mathrm{~g} / \mathrm{kg}$ kuiva-ainetta (ka) ja ka-pitoisuus 341 g/kg. Seosrehun ka:sa oli 71 g/kg tuhkaa, 158 g/kg raakavalkuaista ja 412 g/kg kuitua.

Eläinten seosrehun syöntiä seurattiin kokeen ajan punnitsemalla lehmäkohtaisesti päivittäin annettu rehu sekä aamuisin edelliseltä päivältä jäänyt tähde. Rehu jaettiin kiskoruokkijalla kaksi tai kolme kertaa päivässä. Ruokintapöydällä oli jatkuvasti tarjolla seosrehua. Seosrehusta otettiin näyte joka toinen päivä analyysiä varten.

Maito. Lehmät lypsettiin parsissa kahdesti päivässä noin klo 6.30 ja 17.00. Maitomäärä mitattiin päivittäin ja maidosta otettiin näytteet maidon koostumuksen määrittämiseksi kokeen kahtena ensimmäisenä ja kahtena viimeisenä päivänä. Lisäksi arvioitiin maidon aistinvarainen laatu eli haju ja maku hemiselluloosaliuosten käytön alkamisesta kokeen loppuun saakka jokaisella lypsykerralla.

Veden kulutuksen lähtötason määrittäminen. Kokeen alussa 2,5 päivän ajan selvitettiin lehmäkohtaisesti päivittäinen vedenkulutus. Vesi laitettiin muovilaatikoihin tarjolle ruokintapöydälle lehmien eteen ja veden kulutus selvitettiin punnitsemalla tarjottu ja juomaton vesi 1 . koepäivänä kahden tunnin välein ja 2. koepäivänä kolmen tunnin välein. Viimeinen punnitus oli iltatarkastuksen yhteydessä klo 20. Yöksi lehmille jätettiin vettä yhteen laatikkoon noin 25-30 kiloa. Vesi vaihdettiin laatikoihin kaksi kertaa vuorokaudessa.

Hemiliuosten maittavuuden mittaaminen. Veden kulutuksen lähtötason mittauksen loputtua kolmantena koepäivänä lehmiä alettiin totuttaa hemiliuoksiin. Klo 12 lehmät saivat kolmen tunnin ajaksi ensin koivuliuosta. Kello 15 laatikkoon vaihdettiin kuusiliuos, joka otettiin pois kello 18. Lehmillä oli samanaikaisesti lisäksi vesilaatikko. Kolmannen koepäivän iltana lehmiltä otettiin vesilaatikot pois kello 20 ja lehmät olivat ilman vettä seuraava yön.

Challenge-testi alkoi neljännen koepäivän aamuna kello 6. Lehmille asetettiin tarjolle vain koivu- ja kuusiliuoksia kello 15 saakka. Laatikot punnittiin kolmen tunnin välein ja kumpaakin hemiliuosta lisättiin tarvittaessa niin, että liuoksia oli aina tarjolla.

Lehmät eivät 15 tunnin vesipaastosta huolimatta olleet juuri koskeneet hemiliuoksiin neljäntenä koepäivänä kello 15 mennessä. Kello 15 lehmille tarjottiin haalealla vedellä laimennettua kuusiliuosta. Tätä laimennettiin suhteessa $1 / 5$ ja sitä lehmät suostuivat yhtä lukuun ottamatta juomaan. Neljännen koepäivän kello 15 ja 5 . koepäivän kello 6 välillä lehmille tarjottiin vain tätä $1 / 5$ laimennettua kuusiliuosta. Juomalaatikot punnittiin kolmen tunnin välein, mutta kello 20.30 ja 6 väliseksi ajaksi laatikoihin jätetiin riittävästi juomaa eikä punnituksia tehty yöllä. Näin lehmiä alettiin asteittain totuttaa hemiliuoksiin. 
Hemiliuoksia alettiin väkevöittää viidennestä koepäivästä kello 6:sta lähtien. Taulukossa 2. ovat päivittäiset hemiliuosten ja veden laimennussuhteet. Kulutusta seurattiin punnitsemalla tarjotut ja juodut määrät neljän tunnin välein. Iltaisin kello 20 lehmien annettiin juoda laatikoista tarjoiltuna vapaasti vettä noin puolen tunnin ajan, ettei niiden tuotos laskisi veden puutteesta. Hemiliuokset jätettiin tarjolle yöksi. Ne vaihdettiin illalla kello 18 punnituksen yhteydessä ja uusi laimennussuhde vaihdettiin laatikoihin aamuisin kello 6. Lehmät joivat kuusiliuosta mieluummin, joten sitä kului enemmän. Suuremmista juontimääristä johtuen kuusiliuos loppui eikä sitä riittänyt yhdeksäntenä koepäivänä kuin noin 7 kiloa lehmää kohti. Koetta jatkettiin kuitenkin tarjoamalla lehmille laimentamatonta koivuliuosta kokeen loppuun eli 10. koepäivään kello 6 asti.

Taulukko 2. Hemiliuoksen ja veden laimennussuhde koepäivittäin kello 6 seuraavaan päivään kello 6.

\begin{tabular}{ccc}
\hline Koepäivä & Hemiliuosta & Vettä \\
\hline 5 & 1 & 4 \\
6 & 1 & 3 \\
7 & 1 & 2 \\
8 & 1 & 1 \\
9 & 1 & 0 \\
\hline
\end{tabular}

Hemiliuosten säilyvyyden seuranta. Ensimmäisenä päivänä molemmista hemiliuoksista otettiin näyte, jotka laitettiin kahteen 0,5 litran pakasterasiaan ja suljettiin kannella. Toiset rasiat jätettiin huoneenlämpöön ja toiset laitettiin jääkaappiin. Rasiat avattiin päivittäin ja niiden säilyvyyttä arvioitiin aistinvaraisesti. Liuoksista arvioitiin haju, lajittuneisuus, mahdolliset kuplat, home sekä kirjattiin muut havainnot. Seurantaa jatkettiin niin kauan, kunnes näytteet olivat selkeästi pilaantuneet.

Analyysit. Hemiliuoksista kerättiin päivittäin osanäytteet molemmista liuoksista viikko 1 ja viikko 2 erikseen. Keruun aikana liuoksia säilytettiin kylmiössä ja näytettä kerättiin ämpäriin 2 litraa päivässä. Keruun päätyttyä analyysinäyte pakastettiin $-20{ }^{\circ} \mathrm{C}: s s a$. Seosrehusta otettiin osanäytteet päivittäin jotka yhdistettiin. Hemiliuoksista määritettiin kuiva-ainepitoisuus, tuhka ja typpi. Seosrehusta määritettiin kuiva-aine, tuhka, typpi ja kuitu NDF-menetelmällä MTT:n laboratoriossa Jokioisilla. Analyysit tehtiin käyttäen MTT Kotieläintuotannon tutkimuksen laboratorion standardimenetelmiä. Hemiliuosten hemiselluloosan sokerikoostumus ja ligniinipitoisuus analysoitiin Metlassa.

Maidosta otettiin näytteet kokeen kahtena ensimmäisenä ja kahtena viimeisenä päivänä. Maitonäytteistä määritettiin rasva, valkuainen, laktoosi, urea sekä solupitoisuus Valio Oy:n laboratoriossa.

\section{Tulokset ja niiden tarkastelu}

Hemiliuosten koostumus. Hemiliuosten koostumus on esitetty taulukossa 3. Liuokset olivat hyvin laimeita ja niiden tuhkapitoisuudet olivat erittäin matalia. Samanlaisesta prosessista peräisin olevan hemiselluloosarehun vastaavat tuhka- ja raakavalkuaispitoisuudet olivat $11,7 \mathrm{~g} / \mathrm{kg} \mathrm{5,0} \mathrm{g} / \mathrm{kg} \mathrm{ka}$ (Sormunen-Cristian ym. 2012). Kuusiliuoksen ka-pitoisuus oli lähes puolta pienempi kuin koivusta uutetun. Tällä on saattanut olla vaikutusta kuusiliuoksen parempaan maittavuuteen.

Koivu- ja kuusiliuosten hemiselluloosan sokerikoostumus poikkesi toisistaan. Koivun sokereista lähes $80 \%$ oli ksyloosia kun kuusessa sitä oli alle $20 \%$. Kuusen tärkein sokerikomponantti oli mannoosi, jota oli puolet kaikista sokereista. Sokereiden yhteismäärä oli kuusessa suurempi kuin koivussa. Molemmissa liuoksissa oli runsaasti ligniiniä ja koivussa vielä enemmän kuin kuusessa. Ligniinistä märehtijä ei saa energiaa, joten ligniinin suuri määrä laimentaa hemiliuosten kuiva-aineen energiapitoisuutta. 
Taulukko 3. Kuusesta ja koivusta uutettujen hemiliuosten koostumus.

\begin{tabular}{lcc}
\hline & Koivu & Kuusi \\
\hline Kuiva-aine (ka; g/kg) & 27.2 & 15.7 \\
Ka:ssa (g/kg) & & \\
$\quad$ Tuhka & 0.6 & 1.0 \\
Raakavalkuainen & 11.5 & 13.9 \\
Ligniini & 272 & 209 \\
& & \\
Hemiselluloosan sokerikoostumus (g/kg ka) & \\
Mannoosi & 18 & 391 \\
Glukoosi & 17 & 95 \\
Galaktoosi & 19 & 86 \\
Ksyloosi & 482 & 135 \\
Arabinoosi & 9 & 37 \\
Ramnoosi & 11 & 7 \\
Glukuronihappo & 1 & 1 \\
Galakturonihappo & 21 & 17 \\
Metyyliglukuronihappo & 35 & 14 \\
Yhteensä & 612 & 783 \\
\hline
\end{tabular}

Vedenkulutuksen mittaus. Lehmät joivat ensimmäisenä koepäivänä 55 kiloa ja toisena koepäivänä 61 kiloa vettä vuorokaudessa. Lisäksi seosrehun mukana saatu vesimäärä oli 28 kiloa kumpanakin vuorokautena. Tässä kokeessa mitattu veden kulutus oli hieman alhaisempi kuin Kuoppalan (2004) saama tulos $71.5 \mathrm{~kg}$. Vedenkulutukseen vaikuttavat mm. lehmien kuiva-aineen syönti ja tuotostaso, perusrehujen kosteuspitoisuus ja ympäristön lämpötila.

Totuttelu koivu- ja kuusiliuoksiin. Kolmantena koepäivänä lehmien annettiin tutustua kumpaankin hemiliuokseen. Lehmät eivät juurikaan juoneet kumpaakaan liuosta lehmää 140 lukuun ottamatta, joka joi kuusiliuosta noin kaksi kiloa.

Challenge-testi. Neljäntenä koepäivänä challenge-testissä lehmät eivät osoittaneet kahta poikkeusta (lehmät nro 140 ja 106) lukuun ottamatta minkäänlaista kiinnostusta hemiliuoksia kohtaan (taulukko 4).

Taulukko 4. Lehmäkohtaiset koivu- ja kuusihemiselluloosaliuosten juontimäärät challenge-testissä neljäntenä koepäivänä kello 6-15.

\begin{tabular}{lcc}
\hline \multirow{2}{*}{ Lehmä nro } & \multicolumn{2}{c}{ Juotu liuosmäärä, kg/lehmä } \\
\cline { 2 - 3 } & Koivu & Kuusi \\
\hline 106 & 2.3 & 4.1 \\
133 & 0.5 & 4.5 \\
140 & 3.4 & 21.1 \\
176 & 0.2 & 0.5 \\
3316 & 0.3 & 0.1 \\
4268 & 0.2 & 0.2 \\
\hline
\end{tabular}

Koivu- ja kuusiliuosten kulutuksen seuranta ja muutos. Challenge-testin jälkeen kello 15 hemiliuoksia alettiin laimentaa haalealla vedellä. Lehmät olivat olleet jo 16 tuntia ilman vettä, mikä voi jo vaikuttaa tuotokseen ja nestetasapainoon. Lehmä nro 4268 oli poikkeus, sillä se ei suostunut juomaan laimennosta 1/5 eikä myöskään tästä laimempaa liuosta. Tämä lehmä joi ainoastaan vettä. Hemiliuoksia väkevöitettiin kokeen edetessä joka aamu kello 6. Maanantaina 8 koepäivänä laimennussuhde oli jo $1 / 2$ ja 9 koepäivän aamusta kokeen loppuun eli 10 päivään kello 6 saakka lehmille tarjottiin laimentamattomia hemiliuoksia. 
Kuusiliuos oli alusta asti selvästi maittavampaa, joten sen kulutus oli selvästi koivuliuosta suurempaa (taulukko 4). Kuusiliuos loppuikin kesken eikä sitä ollut jäljellä 9. koepäivän aamuna tarjottavaksi laimentamattomana kuin noin 7 kg lehmää kohti. Vähäisestä määrästäkin huolimatta kävi hyvin selväksi, että lehmät olivat tottuneet kuusiliuoksen makuun. Ne joivat suorastaan ahneesti laatikkoon kaadettua laimentamatonta kuusiliuosta 9. koepäivänä eli 5. päivänä, jolloin hemiliuoksia oli tarjolla. Koivu maittoi edelleen selvästi huonommin kuin kuusi. Kuusiliuoksen loputtua lehmät kuitenkin joivat varsin hyvin koivuliuostakin. Veden puute saattoi lisätä vähemmän houkuttelevan koivuliuoksen juontia viimeisenä kokonaisena koepäivänä (taulukko 5.)

Laimennetut hemiliuokset vaihdettiin uusiin joka ilta, joten liuokset olivat koko ajan melko tuoreita eikä maittavuus heikentynyt liuosten vanhentumisen vuoksi. Viidennen ja kuudennen koepäivän eli 2. ja 3. koivuliuoksen tarjollaolopäivien välillä lehmät lisäsivät juontia nopeasti. Kuusiliuoksen maittavuudessa tapahtui merkittävä lisäys 6. ja 7. koepäivän välillä (taulukko 5). Osan tästä lisäyksestä selittää ehkä tottuminen, mutta osasyynä saattaa olla lisääntynyt jano, sillä lehmät lypsivät kohtuullisen runsaasti ja kahdella lehmällä (106 ja 140) oli kulunut vasta noin 1,5 kuukautta poikimisesta. Päivien 7 ja 8 väliselle kuusiliuoksen juontimäärän laskulle ei löytynyt selitystä.

Taulukko 5. Lehmien kuluttaman veden ja hemiliuosten määrä (kg/vrk) sekä maitotuotos (kg/vrk).

\begin{tabular}{cccccccc}
\hline $\begin{array}{c}\text { Koe- } \\
\text { päivä }\end{array}$ & $\begin{array}{c}\text { Koivu- } \\
\text { liuos }\end{array}$ & $\begin{array}{c}\text { Kuusi- } \\
\text { liuos }\end{array}$ & $\begin{array}{c}\text { Laimennos- } \\
\text { vesi }\end{array}$ & $\begin{array}{c}\text { Juoma- } \\
\text { vesi }\end{array}$ & $\begin{array}{c}\text { Vesi } \\
\text { rehusta }\end{array}$ & $\begin{array}{c}\text { Vesi } \\
\text { yhteensä }\end{array}$ & Maito \\
\hline 1 & 0 & 0 & 0 & 57.9 & 34.0 & 91.9 & 24.7 \\
2 & 0 & 0 & 0 & 61.6 & 33.0 & 94.6 & 27.6 \\
3 & 0.1 & 0.4 & 0 & 47.7 & 34.5 & 82.7 & 26.9 \\
4 & 1.1 & 12.8 & 36.3 & 5.6 & 37.9 & 93.5 & 23.8 \\
5 & 1.5 & 8.6 & 40.3 & 8.5 & 39.3 & 98.0 & 21.9 \\
6 & 3.2 & 9.7 & 38.6 & 9.4 & 33.6 & 94.2 & 24.5 \\
7 & 6.4 & 17.0 & 47.4 & 5.8 & 36.6 & 112.8 & 24.3 \\
8 & 9.0 & 16.5 & 25.5 & 14.5 & 37.5 & 102.5 & 25.6 \\
9 & 35.8 & 7.1 & 0.0 & 17.2 & 36.8 & 95.8 & 24.1 \\
\hline
\end{tabular}

Vain yksi lehmä sai 33.5 kg vettä 4. koepäivänä.

Kuusiliuos loppui yhdeksännen koepäivän aamuna, lehmää koti oli tarjottavissa vain noin 7 kg.

Lehmäkohtaiset erot maittavuudessa Lehmien välillä oli suuria eroja hemiselluloosaliuosten maittavuudessa. Lehmä nro 140 joi selvästi innokkaimmin. Hemiliuokset maittoivat tälle lehmälle niin hyvin, että se ei juonut vettä lainkaan 5., 6. ja 7. päivän iltana, vaikka sitä juotavaksi tarjottiin. Myös lehmä nro 106 joi liuoksia hyvin ja oli ainoa joka joi enemmän koivu- kuin kuusiliuosta.

Lehmä nro 4268 joi liuoksia selvästi vähiten. Iltaisin vettä kului selvästi janoon ja tämä lehmä joi lähes koko veden tarjolla oloajan. Kolme eniten hemiliuoksia juonutta lehmää olivat myös kolme runsastuottoisinta lehmää. Näiden lehmien suuri veden tarve saattoi mennä maittavuuden edelle hemiliuosten juonnissa.

Vaikutukset syöntiin ja tuotokseen sekä maidon pitoisuuksiin. Veden saanti hemiliuoksista, juomavedestä ja rehusta sekä maitomäärät on esitetty taulukossa 5. Veden saanti rehusta lisääntyi hieman hemiliuosten tarjolle tulon jälkeen. Lisäksi liuosten juontimäärät lisääntyivät kokeen loppua kohti. Näiden tekijöiden vuoksi veden saanti oli suurempi kokeen neljännestä päivästä alkaen verrattuna kokeen alkupäivinä mitattuun vedenkulutuksen lähtötason.

Maitotuotos laski hetkellisesti Challenge-testin jälkeen, mutta kokeen lopussa se palasi ennalleen. Syöntimäärät näyttäisivät olevan suurempia hemiliuosten käytön alettua verrattuna kolmen ensimmäisen koepäivän syöntimääriin. Lehmien virtsa oli väriltään tummaa ja vaikutti siltä, että virtsan määrä olisi ollut normaalia vähäisempi, mutta sitä ei mitattu. Sonta oli löysää hemiliuosten tarjollaolopäivinä. Voidaan sanoa, että hemiliuoksilla ei ollut haitallisia vaikutuksia koelehmiin. 
Muutokset maidon pitoisuuksissa olivat vähäisiä verrattaessa kokeen kahta ensimmäistä ja kahta viimeistä koepäivää (taulukko 6). Ainoastaan rasvapitoisuuden nousu oli havaittavissa.

Riippuen hemiliuosten ka-pitoisuudesta lehmien voidaan arvioida saavan noin 1-2 kg hemiliuosten kuiva-ainetta päivässä, jos hemiliuosta käytettäisiin lehmien pääasiallisena juomana. Hemiliuosjuotto voisi vähentää lehmien väkirehuannosta vastaavalla määrällä. Hemiliuosten todelliset vaikutukset rehuannoksen vapaaehtoiseen syöntiin, rehuannoksen sulatukseen, ravintoaineiden saantiin ja maidontuotantovaikutukseen vaatisivat varsinaisen maidontuotantokokeen järjestämisen, jossa hemiliuoksia tarjotaan pidemmän aikaa ja kontrollikäsittelynä käytetään ryhmää, joka ei saa hemiliuosta.

Taulukko 6. Maidon koostumus.

\begin{tabular}{cccccc}
\hline Koepäivä & Rasva, g/kg & Valkuainen, g/kg & Laktoosi, g/kg & Urea, mmol/dl & Solut, $\mathrm{kpl}$ \\
\hline $1-2$ & 38.2 & 34.8 & 45.2 & 23.4 & 93000 \\
$8-9$ & 41.9 & 34.0 & 46.2 & 25.8 & 90000 \\
\hline
\end{tabular}

Hemiliuosten säilyvyys. Koivu- ja kuusiliuokset säilyivät yllättävän pitkään ennen kuin näkyviä merkkejä pilaantumisesta ilmestyi rasioissa olleiden nesteiden pinnalle. Lämpimässä säilytetyssä koivuliuoksessa oli hometta näkyvissä ensimmäisen kerran 2,5 kk:n ja kuusiliuoksessa vasta 4,5 kk:n jälkeen. Noin 5 kk säilytyksen jälkeen kummassakaan liuoksessa, joita säilytettiin jääkaapissa, ei ollut havaittavissa mitään merkkejä pilaantumisesta ja seuranta lopetettiin.

\section{Johtopäätökset}

Lehmät eivät juoneet ensin koivu- ja kuusiliuoksia juuri lainkaan mutta ne tottuivat niiden makuun niinikin lyhyessä ajassa kuin neljässä päivässä. Asteittaisella totuttamisella saatiin tässä kokeessa lehmät juomaan hemiliuoksia. Hemiliuoksilla ei ollut merkittäviä vaikutuksia lehmien syöntiin, maitotuotokseen tai maidon koostumukseen. Syönti lisääntyi hieman hemiliuosten käytön alettua. Veden kulutus lisääntyi kokeen edetessä, joten lehmien elimistö ei kuivunut eivätkä ne kärsineet janoa. Liuokset olivat kokeen olosuhteissa erittäin stabiileja.

\section{Kirjallisuus}

Herrick, K.K., Hipppen, A.R., Anderson, J.L., Ranathunga, R.S. \& Abdullah, M. 2011. Lactation performance and digestibility of forages and diets in dairy cows fed a hemicellulose extract. J. Dairy Sci. 95:3342-3353.

Kuoppala, K., Khalili, H. \& Jaakkola, S. 2004. Water intake and drinking behaviour of dairy cows offered grass silage. In: Proceedings of the 38th international congress of the ISAE - International Society for Applied Ethology, Helsinki, Finland 2004 / Editors Laura Hänninen \& Anna Valros. Helsinki: International Society for Applied Ethology. p. 149.

Kuoppala, K., Ahvenjärvi, S., Rinne, M., Joki-Tokola, E., Willför, S., Kitunen, V. \& Spetz, P. 2012. Puusta eristetyn hemiselluloosan sulavuus märehtijöillä in vitro -kaasuntuotantomenetelmän perusteella. Maataloustieteen Päivät 2012. Helsinki. Saatavilla: http://www.smts.fi/Posteri_Rehujen\%20koostumus/Kuoppala_Puusta\%20eristetyn.pdf.

Leppänen, K., Spetz, P., Pranovich, A., Hartonen, K., Kitunen, V. \& Ilvesniemi, H. 2011. Pressurized hot water extraction of Norway spruce hemicelluloses using a flow-through system. Wood Sci. Technol. 45: 223-236.

Panjaitan, T., Quigley, S.P., McLennan, S.R. \& Poppi, D.P. 2010. Effect of the concentration of Spirulina (Spirulina platensis) algae in the drinking water on water intake by cattle and the proportion of algae bypassing the rumen. Animal Production Science 50: 405-409.

Sormunen-Cristian, R., Willför, S., Ahvenjärvi, S., Spetz, P., Kitunen, V. \& Rinne, M. 2012. Kuusesta painekuumavesiuutolla eristetyn hemiselluloosan in vivo -sulavuus pässeillä. Maataloustieteen Päivät $2012 . \quad$ Saatavilla: http://www.smts.fi/Posteri_Rehujen\%20koostumus/Sormunen-

Cristian_Hemin\%20in\%20vivo.pdf. 